\title{
Testing landmark-specific effects on route navigation in an ecologically valid setting: a simulated driving study
}

\author{
Yasaman Jabbari ${ }^{1 *}$ (D, Darren M. Kenney ${ }^{1}$, Martin von Mohrenschildt ${ }^{2}$ and Judith M. Shedden ${ }^{1}$
}

\begin{abstract}
We used a driving simulator to investigate landmark-based route navigation in young adults. Previous research has examined how proximal and distal landmarks influence route navigation, however, these effects have not been extensively tested in ecologically-relevant settings. We used a virtual town in which participants learned various routes while simultaneously driving. We first examined the effect of four different landmark conditions on navigation performance, such that each driver experienced one of four versions of the town with either proximal landmarks only, distal landmarks only, both proximal and distal landmarks, or no landmarks. Drivers were given real-time navigation directions along a route to a target destination, and were then tested on their ability to navigate to the same destination without directions. We found that the presence of proximal landmarks significantly improved route navigation. We then examined the effect of prior exposure to proximal vs. distal landmarks by testing the same drivers in the same environment they previously encountered, but with the landmarks removed. In this case, we found that prior exposure to distal landmarks significantly improved route navigation. The present results are in line with existing research on route navigation and landmarks, suggesting that these findings can be extended to ecologically-relevant settings.
\end{abstract}

Keywords: Spatial navigation, Proximal landmarks, Distal landmarks, Driving simulator, Virtual environment, Survey knowledge, Route learning, Wayfinding

\section{Significance statement}

During wayfinding and navigation, landmarks influence our spatial encoding and representation of the environment. Real world navigation is often paired with complex body coordination tasks such as walking or driving rather than simple keyboard or joystick movements. In this study, we assessed whether existing route-based navigation findings extend to ecologically-relevant settings by combining navigation and driving in an immersive driving simulator. Our results suggest that guided navigation while driving (e.g., GPS systems) may be facilitated differentially by proximal vs. distal landmarks. Route

\footnotetext{
*Correspondence: jabbariy@Mcmaster.ca

1 Department of Psychology, Neuroscience and Behaviour, McMaster

University, Hamilton, ON, Canada

Full list of author information is available at the end of the article
}

navigation was facilitated when the initial guided navigation was in the presence of proximal landmarks, suggesting proximal landmarks may be more specifically associated with navigation decisions. When tested in an environment without any landmarks, prior exposure to distal landmarks in that same environment improved navigation, suggesting that distal landmarks may facilitate orientation knowledge of the space. This work may be important for designing GPS navigation systems that improve navigation by taking advantage of spatial memory.

\section{Introduction}

As we move through a spatial environment, information about our relative position is updated. Humans are flexible navigators, actively changing navigation strategies depending on the available information such as 
external landmark cues in the environment (Caduff \& Timpf, 2008; De Condappa, 2016; Foo et al., 2005; Siegel \& White, 1975; for a review, see Montello, 2005). Landmarks can be categorized as either proximal or distal (Caduff \& Timpf, 2008; Chan et al., 2012; Cohen \& Schuepfer, 1980; Jansen-Osmann, 2002; Stankiewicz \& Kalia, 2007; Steck \& Mallot, 2000). Proximal landmarks are visible from a short distance and can provide local positional information (Chan et al., 2012; Steck \& Mallot, 2000; Wilson \& Alexander, 2008), whereas distal landmarks are visible from far distances (e.g., the moon or a city tower) and can facilitate acquisition of map-like orientation information (Hamilton et al., 2002; Jacobs et al., 1997; Steck \& Mallot, 2000).

Landmarks are important for the generation and application of two qualitatively different types of spatial knowledge: survey and route knowledge (Evans et al., 1984; Jansen-Osmann \& Fuchs, 2006; Montello, 2005; O'Laughlin \& Brubaker, 1998; Waller \& Lippa, 2007; Wiener et al., 2009). Survey knowledge is based on cognitive maps, which are mental representations of the environment that reflect the spatial configuration of landmarks relative to one another (O'Keefe \& Nadel, 1978; Taylor et al., 1999; Thorndyke \& Hayes-Roth, 1982; Tolman, 1948; Zimmer, 2004). Some work has shown that distal landmarks best support survey knowledge because they provide global orientation information about the environment (De Condappa, 2016; Hamilton et al., 2002; Jacobs et al., 1997; Livingstone-Lee et al., 2011; Mueller et al., 2008).

In contrast, route knowledge is a relatively basic navigation strategy that requires knowledge of a particular sequence of landmarks and turn decisions (Andersen et al., 2012; Daniel et al., 2003; Hartley et al., 2003; Klatzky, 1998; Siegel \& White, 1975; Waller \& Lippa, 2007). Proximal landmarks support route knowledge by providing intermediate goals along the route (Hurlebaus et al., 2008; Ruddle et al., 2011; Steck \& Mallot, 2000). Successful navigation using route knowledge does not require survey knowledge, and tends to be less cognitively demanding but also less flexible than survey knowledge due to reliance on the sequence of decisions (e.g. Chan et al., 2012; De Condappa, 2016; Hartley et al., 2003; Knierim \& Hamilton, 2011; Steck \& Mallot, 2000; Wilson \& Alexander, 2008). Moreover, the utility of proximal landmarks is limited to a local spatial area, and the view of that space changes with the viewpoint. Accordingly, using proximal landmarks to obtain allocentric information for locating a target is challenging (Benhamou \& Poucet, 1998; Knierim \& Hamilton, 2011; O'Keefe \& Nadel, 1978; Save \& Poucet, 2000).

Many navigation studies assessing route navigation used basic paradigms in which cognitive load was limited to the navigation task itself (Andersen et al., 2012; Bakdash et al., 2008; Carassa et al., 2002; Gardony et al., 2011; Hurlebaus et al., 2008; Janzen \& Turennout, 2004; Knorr et al., 2014; Péruch et al., 1995; Stankiewicz \& Kalia, 2007; Viaud-Delmon \& Warusfel, 2014; Wallet et al., 2011). These studies were tightly controlled and provided internal validity, but we seek to extrapolate the findings to navigation in the real world. Studies that require active driving or walking while navigating in a real environment inevitably involve various confounding actions, but include sensory cues that are not available in a more limited environment, such as cues to production and detection of self-motion (Whishaw \& Wallace, 2003; Poucet \& Save, 2017; Lin et al., 2016; for a review see Chrastil \& Warren, 2012). Moreover, actively driving and navigating associates actions with the relative spatial relations that link landmarks, routes, and allocentric directions (Appleyard, 1970; Chrastil \& Warren, 2012; Duncan, 1984; Maguire et al., 2000, 2006). An immersive virtual environment can provide a more controlled and stable experimental design while bridging behaviour in the laboratory with behaviour in the real world (Appleyard, 1970; Chrastil \& Warren, 2012; Farrell et al., 2003).

A more realistic driving scenario that incorporates simultaneous navigation and driving may present a more demanding situation for drivers, and this may interact with navigation strategies that are cognitively demanding, such as the use of distal landmarks for allocentric navigation (De Condappa, 2016; Waller \& Lippa, 2007). Drivers may tend to be reliant on global positioning systems (GPS) for their navigation, and it has been recognized that outsourcing spatial cognition processing (Clark, 2017; Foglia, \& Wilson, 2013; Gračanin, 2018; Hollan et al., 2000; Soler et al., 2017; Wilson, 2002) may result in significantly poorer spatial memory for locations (Hejtmánek et al., 2018; Ishikawa et al., 2008; Leshed et al., 2008; Münzer et al., 2006; Willis et al., 2009). Therefore, understanding how landmarks influence real-time route navigation in drivers is an important first step to understanding how the existing navigation literature extends to route navigation in the real world.

In the present study we used a driving simulator to simulate a realistic navigation environment. The first goal of our study was to examine the effect of proximal and distal landmarks on route navigation. The second goal was to examine the contribution of prior exposure to proximal and distal landmarks by assessing route navigation in that same environment without landmarks. Our hypotheses were that (1) route navigation would be sensitive to type of landmark, and that (2) route navigation in the absence of landmarks would be sensitive to prior experience with different types of landmarks in that same environment. 


\section{Methods}

\section{Participants}

We recruited 128 participants (55 females) between the ages of 18 to 31 years old $(M=19.21, S D=2.48)$. These were graduate students who participated as volunteers and undergraduate students who participated for course credit. Participants were screened based on self-reports to have no vision or hearing problems and no sensitivity to cyber sickness or claustrophobia. Self-report questionnaires also estimated familiarity with computers and computerized and virtual games. Participants were randomly assigned to one of four groups (32 per group). Six participants were removed due to technical issues. Each group received a different type of landmark during the training block: combined (proximal and distal) (PD, $n=30$ ), distal (D, $n=31$ ), proximal ( $\mathrm{P}, n=30)$, or no landmarks $(\mathrm{N}, n=31)$. The experiment was approved by the Hamilton Health Research Ethics Board and complied with the Canadian Tri-Council policy on ethics.

\section{Experimental setup}

Visual stimuli were presented on three $42^{\prime \prime}$ (diagonal) LCD panels, each with a resolution of $1920 \times 1080$ pixels, running at a $60 \mathrm{~Hz}$ refresh rate. The LCD panels were set up in an enclosed environment and aligned in an arc to provide a wide field of view (FOV) of $35^{\circ}$ vertically and $120^{\circ}$ horizontally (Fig. 1). A wide FOV provides a higher viewer capacity that is more akin to driving in a real environment by increasing perception of the self-motion cues in the periphery as participants move through space and make head turn movements (e.g., Mizell et al., 2002; Narayan et al., 2005; Pausch et al., 1997; Starkweather, 2003). Research has shown that using wide FOV displays is beneficial for navigation performance (e.g., Patrick et al., 2000; Tan et al., 2006; Tyndiuk et al., 2007).

Participants sat in a bucket car seat positioned to maintain an approximate distance of $120 \mathrm{~cm}$ between the participants' eyes and the central LCD screen. The driving interface consisted of a Logitech steering wheel and gas and brake pedals (Logitech International S.A., Lausanne, Switzerland). There were two cameras inside the simulator pod for experimenter monitoring purposes; one provided a front view of the participant, and the other provided a bird's eye view of the interior. An intercom system allowed communication between the participant and the experimenter. Data from the steering wheel and pedals were continuously recorded at a sampling rate of $60 \mathrm{~Hz}$.

\section{Virtual environment}

The dynamic visual simulation of the town was coded in $\mathrm{C}++$ using the Vega Prime (Presagis) library. The

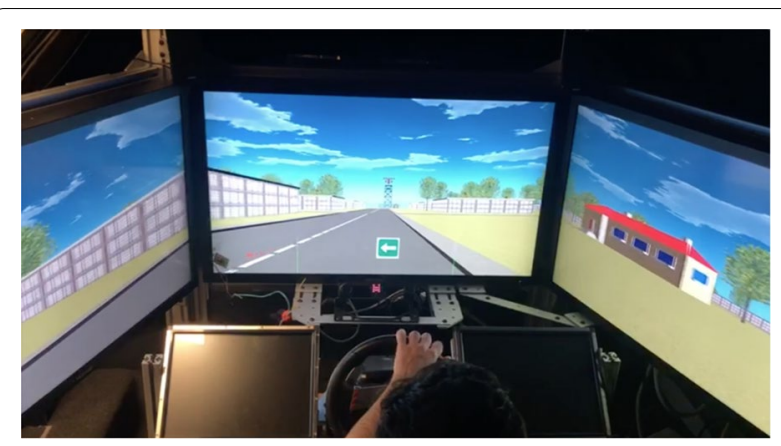

Fig. 1 Driving simulator from the participant's view as they completed the guided navigation phase of the combined landmark group (PD group). Participants controlled their vehicle with a steering wheel, gas, and brake pedals. The small screens on the left and right of the steering wheel were not used in this experiment. In this example, a tall radar tower at the edge of the town (distal landmark), and a colorful house at the upcoming intersection (proximal landmark) are visible to the driver. A white/green navigation arrow briefly presented at the bottom of the central screen indicates a left turn at the next intersection

small virtual town consisted of a $3 \times 3$ grid of city blocks defined by a $4 \times 4$ grid of roads (Fig. 2). The target destination was a dead-end at the center of the town. All conditions included visually-similar generic buildings throughout the town (see Fig. 1), except for the landmarks which were distinctive. There were two types of landmarks: 4 proximal landmarks and 4 distal landmarks. Proximal landmarks were 3D renderings of a church, a store, a house, and a gas station. Proximal landmarks were located on corner lots at central intersections and were visually obstructed by the surrounding generic buildings so that they were only visible from nearby locations and could not be used as distal landmarks.

Distal landmarks were 3D renderings of a radar tower, a control tower, a water tower, and a wind tower, located beyond the outer boundaries of the town and tall enough to be visible from most locations in the town when facing in the right direction. In experimental conditions in which the proximal and distal landmarks were not present, the visually-similar generic buildings and the surrounding roads looked similar from each of the internal intersections of the town. Without the distal landmarks, the town's edges were not differentiable from each other and due to the render distance were visible to navigators only when they were driving on a road close to the edge. Although there is an illusion of simplicity when looking at the top-down view of the town in Fig. 2 (top-down view was not provided to participants), navigation was challenging enough to elicit strong individual variation in route-navigation performance. 


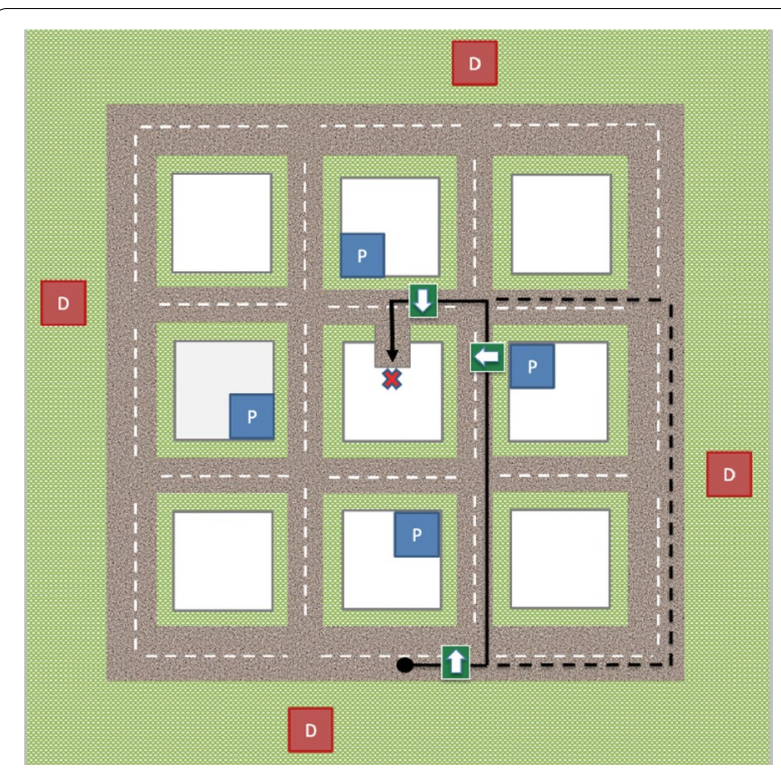

Fig. 2 Bird's eye view of the virtual town in the same condition (not shown to the participant). The red " $\mathrm{D}$ " squares indicate locations of distal landmarks, and the blue "P" squares indicate locations of proximal landmarks. An example training route is denoted with a black solid line from start position (black circle) to target location (red X). The arrows indicate the approximate point at which the white/green navigation arrows appear as the driver approaches the intersection during the guided navigation phase. The dashed black line is an example of an alternate route the driver might take during the testing phase if they failed to follow the trained route (learned in the guided navigation phase) but successfully reached the target location (e.g., partial route retracing)

\section{Procedure}

A demographic questionnaire collected self-report data including gender and average daily hours of driving, playing video/computerized games, and computer use outside of games. Participants practiced driving in the simulator (e.g. making left and right turns, accelerating and braking) until they were comfortable with the operation of the steering wheel, pedals, and immersive visual environment.

The experimental design consisted of 2 blocks (a Training block followed by a Transfer block), 2 phases per block (a Guided Navigation phase followed by a Testing phase), and 4 navigation trials per phase. Participants were randomly assigned to 1 of 4 groups defined by the type of landmarks presented in the Training block: both proximal and distal landmarks combined (PD), proximal landmarks only (P), distal landmarks only (D), or no landmarks $(\mathrm{N})$. Importantly, landmarks were present during the Guided Navigation and Testing phases of the Training block only.

Training block: In the Guided Navigation phase of the Training block, participants were guided along 4 different routes. Each route had a different starting point, traversed four intersections (4 decision points), and terminated at the target destination (dead-end road in the centre of town). Navigation at each intersection was guided by a left, right, or forward arrow displayed at the bottom of the screen as the car approached the intersection. In the Testing phase, the same 4 routes were tested in the same order, but this time without the guidednavigation arrows. For each route, the car was placed at the same starting point as the guided navigation phase. Participants were instructed to drive to the target destination by retracing the learned route exactly. However, if they took a wrong turn or were unable to remember the exact route, they should try to reach the target destination via an alternate route. There was a $90 \mathrm{~s}$ time limit after which the trial terminated even if the participant failed to reach the target destination.

Transfer block: The procedure in the Guided Navigation and Testing phases was the same as in the Training block, except for two differences: (1) there were no landmarks present for any of the 4 landmark groups, and (2) a different set of 4 routes were used for all 4 landmark groups.

The Training and Transfer blocks were each about $10 \mathrm{~min}$ in duration and participants were offered a short break (2-4 min) after the Training block. The entire experiment was about $45 \mathrm{~min}$ in duration, including informed consent, the demographic questionnaire, driving practice, instructions, the two experimental blocks, and final debriefing which clarified the design and purpose of the experiment.

\section{Data analysis}

We assessed route navigation performance in the testing phase of each Training and Transfer block by evaluating two dependent variables: success and route retracing.

Success: Success was the percentage of trials for which the target destination was found before the $90 \mathrm{~s}$ time limit. There were 4 trials (routes) in each testing phase, and the outcome of each trial was either a success or fail, thus success rate was treated as a binomial variable.

Route retracing: In the testing phase, participants were instructed to find the target destination by retracing the corresponding routes from the guided navigation phase, however they were permitted to take alternate routes. Route retracing included all success and failure trials to capture memory for the learned route. The route retracing score was calculated as a percentage of the length of the route taken in the testing phase that overlapped with the route taken in the guided navigation phase (see Fig. 2). A route retracing score of $100 \%$ would indicate that the route taken in the testing phase overlapped the entire length of the guided navigation route. 
Generalized linear mixed model (GLMM): Our models included two independent fixed variables of Landmark Group (PD, P, D, \& N) and Block (training \& transfer). The Trial Order variable was analyzed as both fixed (Trial Order) and random (Trial Order x participants). Treating Trial Order as a fixed effect accounted for overall learning effects; treating Trial Order as a random slope across participants accounted for individual differences in learning rates. Since the dependent variable success $(S)$ was a binomial variable (success or failure), we used a logit link function to create a logistic regression model, by applying a generalized linear mixed model (GLMM) (Agresti, 2015; Dunteman \& Ho, 2006). In the regression summary, the first category is used as a reference category. Which category is selected as the reference does not affect the results, it only determines the specific comparisons that the model reports. We selected PD (training block) as the reference category. We hypothesized that due to the availability of both types of landmarks, this group would have the highest level of predicted value (success). Thus, using PD as the reference category against which the other landmark conditions are compared is an intuitive way to interpret the output of the model.

The four questionnaire variables were gender, average daily gaming computer hours, average daily non-gaming computer hours, and average daily driving hours. Of the questionnaire variables, only computer hours predicted success $(z=2.227, p=0.026)$, and none predicted route retracing. Final models excluded these non-significant questionnaire predictor variables (see Wilkinson notation below). The estimate $(\beta)$ of each term in the logistic regression model is the log-odds ratio between the term and the reference category. The odds ratio (OR) is equal to $\exp (\beta)$ and describes the ratio of the likelihood of success between the two categories. Since route retracing was a continuous variable, it was modelled with a linear mixed model (LMM) with the same independent variables. In Wilkinson notation (Wilkinson \& Rogers, 1973) the models are as follows:

Success (S):

$$
\begin{aligned}
\mathrm{S} & \sim \text { landmark group } * \text { block }+ \text { trial } \\
& + \text { computer hrs }+(0+\text { trial } \mid \text { participants })
\end{aligned}
$$

Success learning effect:

$$
\mathrm{S} \sim \text { landmark group } * \text { trial }+ \text { computer hrs }
$$$$
+(0+\text { trial } \mid \text { participants })
$$

Route Retracing (RR):

$$
\begin{aligned}
& \mathrm{RR} \sim \text { landmark group } * \text { block } \\
& \quad+\text { trial }+(1+\text { trial } \mid \text { participants })
\end{aligned}
$$

\section{Route retracing learning effect:}

$$
\mathrm{RR} \sim \text { landmark group } * \text { trial }+(1+\text { trial } \mid \text { participants })
$$

\section{Results}

\section{Success}

The statistical results of the generalized linear mixed model are reported in Table 1 . In the training block, both the D group $(\beta=-1.370, z=-4.117, p<0.001)$ and the $\mathrm{N}$ group $(\beta=-0.838, z=-2.495 ; p=0.0125)$ were less successful in finding the target location compared to the PD group. Success of the P group did not differ from the PD group $(p=0.714)$. Significant interactions revealed that the success in PD across training and transfer blocks differed from those of $\mathrm{D}(\beta=2.413, z=4.843, p<0.001)$ and from $\mathrm{N}(\beta=1.490, z=3.125, p=0.0017)$. No significant interaction was observed for the P group $(p=0.799)$ (Fig. 3 and Table 1).

Pairwise comparisons with Tukey adjustments were

\begin{tabular}{|c|c|c|c|c|c|c|c|}
\hline Landmark*Block & Estimate $(\beta)$ & SE & OR & $\mathrm{Cl}(95 \%)$ & & $z$ value & $\operatorname{Pr}(>|z|)$ \\
\hline PD, Training Block (reference) & 2.805 & 0.414 & 16.52 & 2.01 & 3.64 & 6.770 & $<.001^{* * *}$ \\
\hline P, Training Block & 0.138 & 0.378 & 1.15 & -0.60 & 0.89 & 0.366 & 0.714 \\
\hline$D$, Training Block & -1.370 & 0.332 & 0.25 & -2.04 & -0.73 & -4.117 & $<.001^{* * *}$ \\
\hline$N$, Training Block & -0.838 & 0.336 & 0.43 & -1.51 & -0.19 & -2.495 & $0.0125^{*}$ \\
\hline Transfer Block & 0.254 & 0.443 & 1.29 & -0.62 & 1.12 & 0.573 & 0.566 \\
\hline Trial Order & -0.261 & 0.074 & 0.77 & -0.41 & -0.12 & -3.51 & $<.001^{* * *}$ \\
\hline P: Transfer Block & 0.127 & 0.498 & 1.14 & -0.85 & 1.11 & 0.254 & 0.799 \\
\hline D:Transfer Block & 2.413 & 0.498 & 11.17 & 1.46 & 3.42 & 4.843 & $<.001^{* * *}$ \\
\hline N:Transfer Block & 1.490 & 0.477 & 4.43 & 0.57 & 2.44 & 3.125 & $0.0017^{* *}$ \\
\hline
\end{tabular}
used to test the difference in success between the training and transfer block of each group (a repeatedmeasures comparison). Success in the D group was significantly lower in the training block compared with

Table 1 Results of the generalized linear mixed model with success modelled by Landmark group and Block

Asterisks "***", "**", and "**" denote $p<.001, p<.01, p<.05$, respectively 


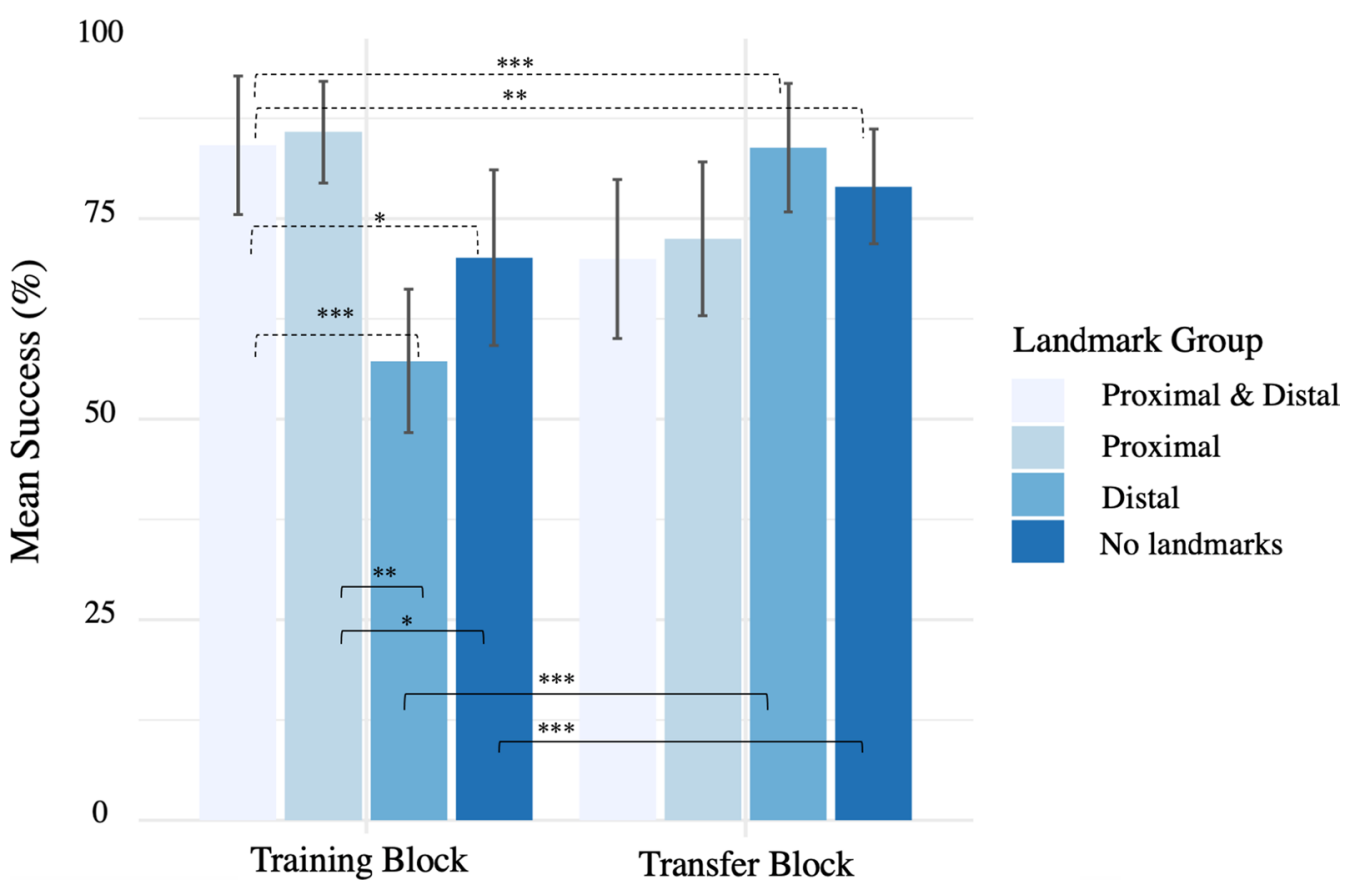

Fig. 3 Success for each Landmark group and Block. Error bars are 95\% confidence intervals. Black dashed lines indicate significant model interactions and black solid lines indicate significant pairwise comparisons. Asterisks "***", "**", and "**" denote $p<.001, p<.01, p<.05$, respectively

the transfer block (Training: $\mathrm{M}=0.572, \mathrm{SE}=0.044$ vs Transfer: $\mathrm{M}=0.838, \mathrm{SE}=0.033 ; \beta=-2.667, z=-5.656$, $p \leq 0.0001)$. Similarly, success in the $\mathrm{N}$ group was lower in the training block (Training: $\mathrm{M}=0.701, \mathrm{SE}=0.041 \mathrm{vs}$ Transfer: $\mathrm{M}=0.790, \mathrm{SE}=0.036 ; \beta=-1.744, z=-3.938$, $p \leq 0.0001)$. No significant difference was observed between the training and transfer block for the $\mathrm{P}$ group (Training: $M=0.858, S E=0.031$ vs Transfer: $M=0.725$, $\mathrm{SE}=0.040 ; \beta=-0.380, \quad z=-0.830, \quad p=0.407)$ or for the PD group (Training: $\mathrm{M}=0.841, \mathrm{SE}=0.033$ vs Transfer: $\mathrm{M}=0.700, \mathrm{SE}=0.042 ; \quad \beta=-0.254, \quad z=-0.573$, $p=0.567)$. Additional pairwise comparisons assessing the success difference between groups within each block showed that, in the training block, success of the P group was significantly higher than the D group $(\beta=1.509$, $z=4.399, p=0.001)$ and the $\mathrm{N}$ group $(\beta=0.977, z=2.823$, $p=0.024)$. There were no other significant pairwise comparisons between the non-referenced groups. Overall, these results suggested that prior exposure to distal landmarks or no landmarks may have facilitated later route navigation in the same environment when no landmarks were present.

\section{Success learning effect}

There was a significant effect of Trial Order on success $(\beta=-0.261, z=-3.51, \quad p<0.001)$, such that success improved over time. We analyzed interactions between
Landmark groups and Trial Order to see if the learning effect differed across groups. We observed a significant interaction of the learning effect for success in the $\mathrm{D}$ group $(\beta=0.360, z=3.493, p \leq 0.001)$ as well as the $\mathrm{N}$ group $(\beta=0.207, z=2,040, p=0.041)$ compared to the PD group, suggesting a positive learning effect across trials for these two groups. We did not observe a significant interaction for the $\mathrm{P}$ group $(\beta=-0.075, z=-0.683$, $p=0.494)$.

\section{Route retracing}

Results of the linear mixed model for Route Retracing are reported in Table 2 . In general, route retracing scores had a strong positive correlation with success $(r=0.619$, $p<0.001$ ). Marginal mean route retracing scores (percent) of successful trials in both training and transfer blocks was high $(\mathrm{M}=79.3, \mathrm{SE}=0.96)$ compared to failed trials $(\mathrm{M}=31.7, \mathrm{SE}=1.68)$.

The $\mathrm{P}$ group had significantly higher route retracing scores than the PD group $(\beta=9.886, t=1.990, p=0.049)$. Route retracing scores in the D group $(p=0.103)$ and the $\mathrm{N}$ group $(p=0.576)$ did not differ from the PD group. A significant interaction revealed that the route retracing in PD across training and transfer blocks differed from those of $\mathrm{D}(\beta=16.585, t=2.753, p=0.006)$ (Fig. 4). There was no significant interaction for the $\mathrm{N}$ group $(p=0.060)$ or the P group ( $p=0.227)$ (Table 2 ). 
Table 2 Results of the linear mixed model with route retracing modelled by Landmark group (PD, P, D \& N) and Block (Training \& Transfer)

\begin{tabular}{|c|c|c|c|c|c|c|}
\hline Block*Landmark & Estimate $(\beta)$ & SE & $\mathrm{Cl}(95 \%)$ & & $t$ value & $\operatorname{Pr}(>|t|)$ \\
\hline PD, Training Block (Intercept) & 82.944 & 4.220 & 74.66 & 91.23 & 19.653 & $<0.001^{* * *}$ \\
\hline P, Training Block & 9.886 & 4.969 & 0.05 & 19.73 & 1.990 & $0.049^{*}$ \\
\hline$D$, Training Block & -8.091 & 4.929 & -17.85 & 1.67 & -1.642 & 0.103 \\
\hline$N$, Training Block & -2.768 & 4.929 & -12.53 & 6.99 & -0.562 & 0.576 \\
\hline Transfer Block & 14.208 & 5.392 & 3.63 & 24.79 & 2.635 & $0.009 * *$ \\
\hline Trial Order & -5.518 & 0.886 & -7.26 & -3.78 & -6.229 & $<0.001^{* * *}$ \\
\hline P, Transfer Block & -7.340 & 6.073 & -19.26 & 4.58 & -1.209 & 0.227 \\
\hline D, Transfer Block & 16.585 & 6.024 & 4.76 & 28.41 & 2.753 & $0.006^{* *}$ \\
\hline N, Transfer Block & 11.341 & 6.024 & -0.48 & 23.16 & 1.883 & 0.060 \\
\hline
\end{tabular}

Asterisks "***", "***", and "**" denote $p<.001, p<.01, p<.05$, respectively

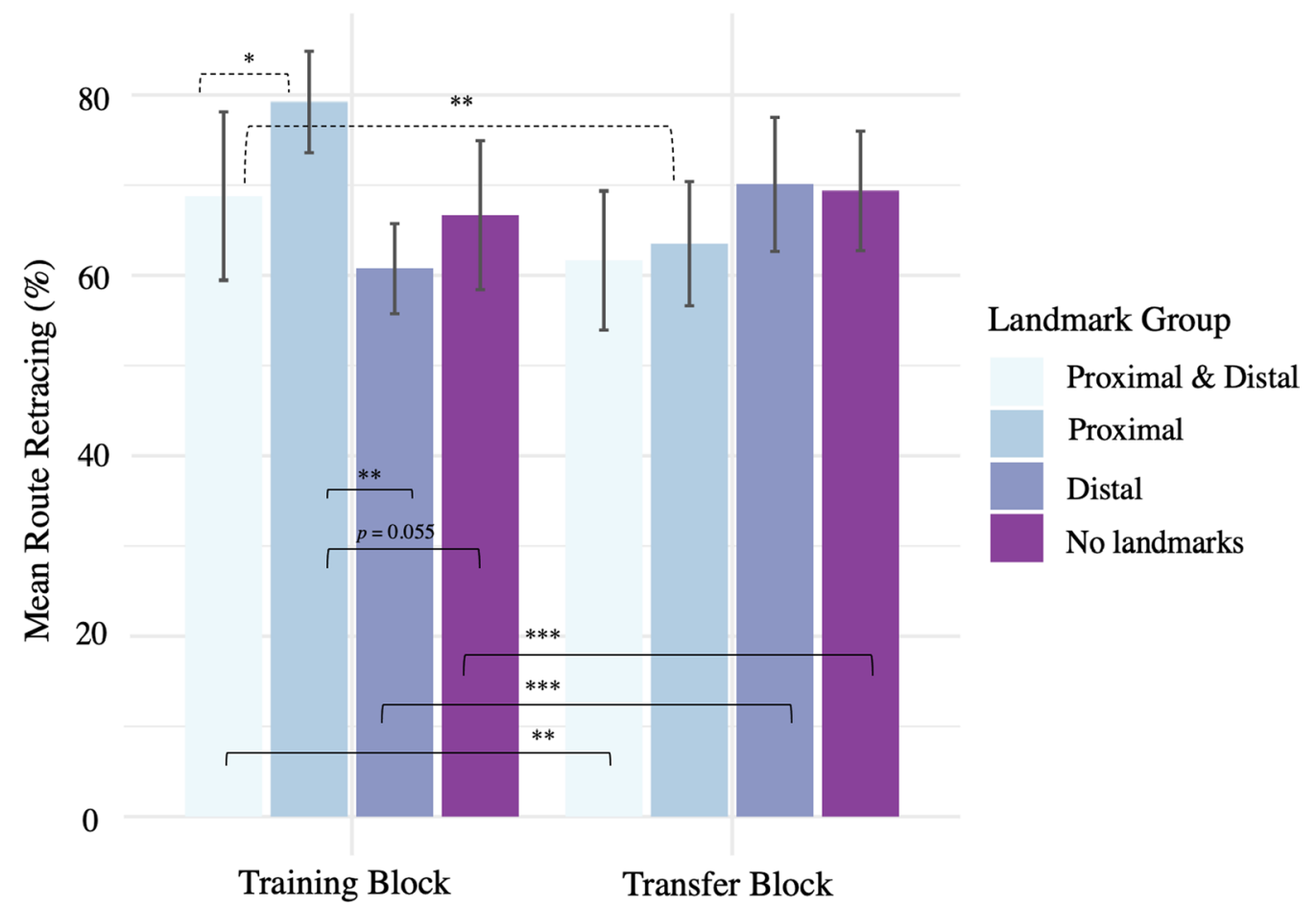

Fig. 4 Route retracing for each Landmark group and Block, for all trials. Error bars are 95\% confidence intervals. Black dashed lines indicate significant model interactions and black solid lines indicate significant pairwise comparisons. Asterisks "***", "**", and "** denote $p<.001, p<.01$, $p<.05$, respectively

Repeated measures pairwise comparisons showed that the route retracing scores of the $\mathrm{D}$ group (Training: $\mathrm{M}=60.79, \mathrm{SE}=2.85$ vs Transfer: $\mathrm{M}=70.13, \mathrm{SE}=2.95$; $\beta=-30.79, t=-5.770, p<0.0001$ ), $\mathrm{N}$ group (Training: $\mathrm{M}=66.73, \mathrm{SE}=3.07$ vs Transfer: $\mathrm{M}=69.40, \mathrm{SE}=3.02$; $\beta=-25.55, t=-4.788, p<0.0001)$, and the PD group (Training: $M=68.84, S E=3.12$ vs Transfer: $M=61.67$, $\mathrm{SE}=3.11 ; \beta=14.21, t=-2.635, p=0.008)$ were significantly different in the training block compared with the transfer block. No significant difference was observed between training and transfer blocks of the $\mathrm{P}$ group (Training: $M=79.25, \mathrm{SE}=2.66$ vs Transfer: $\mathrm{M}=63.54$, $\mathrm{SE}=3.02 ; \beta=-6.87, t=-1.274, p=0.203)$. Pairwise comparison within blocks indicated that, in the training block, route retracing scores of the $\mathrm{P}$ group were significantly higher than the $\mathrm{D}$ group $(\beta=17.977$, $t=3.647, p=0.002)$ and marginally higher than $\mathrm{N}$ group $(\beta=12.654, t=2.567, p=0.055)$. No other significant 
pairwise comparisons were observed between the nonreferenced groups. Overall, these results suggested that in the presence of proximal landmarks only (P group) drivers were more likely to retrace the exact training routes. Moreover, similar to the success results observed in the transfer block, prior driving experience in the presence of distal landmarks appeared to improve route retracing performance in the transfer block in which no landmarks were present.

\section{Route retracing learning effect}

A significant effect of Trial Order on route retracing was observed $(\beta=-5.518, t=-6.229, p<0.001)$. There was a significant interaction of the learning effect for route retracing scores in the $\mathrm{D}$ group $(\beta=3.082, t=2.256$, $p=0.0243$ ) compared to the PD group, indicating a positive learning effect across the order of trials.

\section{Discussion}

Navigation research has shown that there are differences in the way that proximal vs. distal landmarks influence survey vs. route knowledge (Bullens et al., 2011; De Condappa, 2016; Doeller \& Burgess, 2008; Hurlebaus et al., 2008; Steck \& Mallot, 2000; Wilson \& Alexander, 2008). Our goal in the present study was to understand whether and how these findings extend to route navigation while actively driving. We used a driving simulator to assess route navigation memory in an ecologically-relevant virtual town. We manipulated the presence of different types of landmarks in the training block and tested the effect of prior exposure to different types of landmarks on route navigation in the transfer block where no landmarks were available. In each block, we operationalized route navigation performance in two ways: "success", which was the binomial record of the passed or failed trials in the testing phase, and "route retracing", which was the percentage of overlap between the routes taken in the guided navigation and testing phase.

\section{Success}

In the training block, groups exposed to proximal landmarks (PD and P groups) had significantly higher success than groups exposed to distal or no landmarks (D and $\mathrm{N}$ groups). This is consistent with past research showing that proximal landmarks support route knowledge (e.g., Hurlebaus et al., 2008; Ruddle et al., 2011). Proximal landmarks provide local relative positional information (Benhamou \& Poucet, 1998; Biegler \& Morris, 1996) which is useful in route-based navigation tasks. Even though the presence of proximal landmarks in the training block significantly improved route learning, the relatively poorer performance of the PD compared to the $\mathrm{D}$ group in the transfer block suggested that the mere presence of the distal landmarks is not what facilitated successful route navigation, but rather the lack of proximal landmarks. In other words, drivers' successful use of proximal landmarks when they were available resulted in less well-formed survey-like representations of the environment; this hurt performance when subsequently tested in the absence of landmarks (transfer block). We suggest that when proximal landmarks were not available in the training block (e.g. the $\mathrm{D}$ and $\mathrm{N}$ groups), drivers formed a more effective map-like representation of the environment which supported route navigation in the absence of landmarks in the transfer block.

\section{Route retracing}

The same general pattern of results was observed in the route retracing measure, corroborating the success results. The route retracing score was an indicator of successful guided navigation phase route learning. Participants were encouraged to navigate by retracing the routes learned in the guided navigation phase, which were the most efficient routes to the target destination, but were allowed to take alternate routes.

In the training block, the $\mathrm{P}$ group had significantly higher route retracing scores than all other groups (PD, $\mathrm{D}$, \& $\mathrm{N}$ groups). This suggests that in the presence of proximal landmarks drivers are more likely to retrace the learned routes from the guided navigation phase, whereas in the presence of distal landmarks or absence of proximal landmarks drivers can afford more flexible navigation. Drivers benefit from proximal landmarks during navigation as they can be associated directly to turns at intersections. Distal landmarks do not provide the same highly reliable local positional information because they are too distant to link a specific turn direction to a particular intersection. However, drivers may still attend to distal landmarks when learning a route and this will lead to better map-like knowledge.

In the transfer block, where landmarks were not available, prior exposure to distal landmarks increased the retracing scores of the $\mathrm{D}$ group. This could mean that even though distal landmarks were not as useful to route retracing as proximal landmarks, they did help to generate a mental representation of the town which was helpful for route retracing in the transfer block. An important question is why precise route retracing in the PD group was lower when compared to the $\mathrm{P}$ group in the training block or D group in the transfer block. Presence of both types of landmarks together might draw attention away from efficient use of the navigational strategy that uses either type of landmarks. Efficient navigation requires the ability to dynamically weight different navigation strategies based on available landmarks (Montello, 2005; Steck \& Mallot, 2000; Wiener et al., 2004, 2009). Drivers in the 
PD group may have attempted to use both proximal and distal landmarks, leading to a lower route retracing score.

\section{Summary}

Many navigation studies have analyzed joystick or keyboard responses in tasks involving desktop virtual environments (e.g., Andersen et al., 2012; Bakdash et al., 2008; Carassa et al., 2002; Gardony et al., 2011; Hurlebaus et al., 2008; Janzen \& Turennout, 2004; Knorr et al., 2014; Péruch et al., 1995; Stankiewicz \& Kalia, 2007; ViaudDelmon \& Warusfel, 2014; Wallet et al., 2011). Some studies have used both real and virtual setups (e.g., Farrell et al., 2003; Grant \& Magee, 1998), and several have examined navigation while participants walked in the real world (e.g., Münzer et al., 2006; Wallet et al., 2008; Willis et al., 2009; Zhong \& Kozhevnikov, 2016). A few studies have assessed navigation and driving in the real world (e.g., Antrobus et al., 2016; Fu et al., 2019; Stülpnagel \& Steffens, 2012), and only a few have tested navigation using an immersive virtual reality driving simulator (e.g., Cochran \& Dickerson, 2019; Kunishige et al., 2019; Pankok Jr \& Kaber, 2018; Smyth, 2007; Yi et al., 2015). It could be argued that navigating while driving is substantially more difficult than navigating by means of keyboard or joystick for multiple reasons. There is additional cognitive load due to following the rules of the road, staying in the lane, and making turns at the appropriate speed. Additional sensorimotor control involved in driving with a steering wheel and pedals might also impact navigation performance. Other studies have demonstrated that cognitive load (e.g. cell phone use) while driving negatively impacts memory for landmarks (e.g. Blalock et al., 2014). It is possible that the increased cognitive load could influence spatial memory and therefore route navigation.

We assessed navigation in an ecologically valid setup. We provided a large-scale virtual environment which required an active application of wayfinding strategies (e.g., Diersch \& Wolbers, 2019; Loomis et al., 1993; Poucet, 1993; Wolbers \& Wiener, 2014; Zhang et al., 2014). Size of the environmental space plays an important role in the emergence and development of allocentric survey-based navigation strategies from egocentric route-based navigation strategies (Ekstrom \& Isham, 2017; Siegel \& White, 1975; Török et al., 2014; Zhang et al., 2014; Zhang et al., 2014). For the D group in the present study, the development of survey knowledge was not observed immediately in the training block, but rather later in the transfer block. This is in accordance with theories indicating that the development of navigational strategies is hierarchical, with egocentric route-based strategies emerging before more cognitively demanding allocentric map-based strategies (e.g.,
Gagnon, et al, 2014; Han \& Becker, 2014; McNamara et al., 1989; Siegel \& White, 1975).

The results of the present study suggest that landmarkspecific effects on route navigation in the extant literature do carry over to the elevated difficulty of navigating while driving in complex virtual environments. Specifically, we found that the presence of proximal landmarks was more likely to result in successful route navigation in the training block. In contrast, the presence of distal landmarks in the training block was more likely to result in successful route navigation in the transfer block, suggesting that drivers may have obtained survey knowledge from the distal landmarks that carried over to route navigation when no landmarks were present.

\section{Limitations and future approaches}

In this study, we used distal and proximal landmarks that simulated those found in a typical urban driving environment. Objects that are more conspicuous relative to their environment tend to function as more salient landmarks (e.g., Caduff \& Timpf, 2008; Sorrows \& Hirtle, 1999). Our salient landmarks were present in the training block only and not the transfer block. A limitation of this design is that landmarks do not tend to disappear in a real environment. A future experiment might set up a scenario to explain the removal of the landmarks (e.g. major construction underway to replace infrastructure in the town). Other tests for survey knowledge could be employed. An advantage to the present design is that it retains active driving in the transfer block, which may be important in revealing transferred route knowledge.

The time required to drive from the starting point to the target destination limited the number of routes tested in each condition, which limited our ability to perform reliable statistical comparisons on route retracing for successful and failed trials separately. Future study designs should address this.

We asked participants to report their driving frequency in an average week. It would have been informative to know their overall driving experience by asking for years of driving experience, because it is conceivable that beginner drivers might experience higher cognitive load from simultaneous driving and navigation compared to more experienced drivers.

We designed the town to be relatively small with only four turns per route to avoid cybersickness. A larger town would provide additional flexibility to incorporate a larger number of routes to test different arrangements of the landmarks. No participants dropped out of the present experiment due to cybersickness, although they were given multiple opportunities to do so without penalty, however, a larger virtual environment might 
increase the probability of cybersickness. There are various approaches that could overcome this limitation and make it a more representative task. For example, reducing the number of stops and turns, and restricting optic flow to a smaller field-of-view has been shown to reduce cybersickness (Lin et al., 2002). The presence of vestibular motion cues may also reduce cybersickness, however this effect remains controversial (Keshavarz et al., 2018; Weech et al., 2020).

\section{Abbreviations}

PD group: Both proximal and distal landmarks; P group: Proximal landmarks; D group: Distal landmarks; N group: No landmarks.

\section{Acknowledgements}

Not applicable.

\section{Authors' contributions}

Y.J, J.M.S and M.V.M developed the study concept. Y.J performed the data collection. Y.J and D.M.K performed data analysis and writing. All authors read and approved the final manuscript.

\section{Funding}

Funding for this study was provided to J.M.S. and M.v.M. by the Natural Sciences and Engineering Research Council of Canada (RGPGP-2014-00051) and the Canadian Foundation for Innovation (2009M00034). These funding sources were not involved in the study design, the collection, analysis and interpretation of data, in the writing of the report, and in the decision to submit this article for publication.

\section{Availability of data and materials}

The datasets, $R$ code, examples of route retracing plots, and Omnibus test results tables are publicly available at: https:/github.com/Jabbariy/Manus cript1_CRPI_2022.

\section{Declarations}

\section{Ethics approval and consent to participate}

The experiment was approved by the Hamilton Health Research Ethics Board and complied with the Canadian Tri-Council policy on ethics. All participants received an information document and provided consent before participation.

\section{Consent for publication}

Not applicable.

\section{Competing interests}

The authors declare that they have no competing interests.

\section{Author details}

'Department of Psychology, Neuroscience and Behaviour, McMaster University, Hamilton, ON, Canada. ${ }^{2}$ Department of Computing and Software, McMaster University, Hamilton, ON, Canada.

Received: 16 March 2021 Accepted: 19 February 2022

Published online: 07 March 2022

\section{References}

Agresti, A. (2015). Foundations of linear and generalized linear models. John Wiley \& Sons.

Andersen, N. E., Dahmani, L., Konishi, K., \& Bohbot, V. D. (2012). Eye tracking, strategies, and sex differences in virtual navigation. Neurobiology of Learning and Memory, 97(1), 81-89. https://doi.org/10.1016/j.nlm.2011. 09.007
Antrobus, V., Burnett, G., \& Skrypchuk, L. (2016). "Turn left at the Fairham Pub" using navigational guidance to reconnect drivers with their environment. In Proceedings of the 8th international conference on Automotive User Interfaces and Interactive Vehicular Applications (pp. 35-42). https:// doi.org/10.1145/3003715.3005392

Appleyard, D. (1970). Styles and methods of structuring a city. Environment and Behavior, 2(1), 100-117.

Bakdash, J. Z., Linkenauger, S. A., \& Proffitt, D. (2008). Comparing decision- making and control for learning a virtual environment: Backseat drivers learn where they are going. Human Factors and Ergonomics Society Annual Meeting Proceedings, 52(27), 2117-2121.

Benhamou, S., \& Poucet, B. (1998). Landmark use by navigating rats (Rattus norvegicus): Contrasting geometric and featural information. Journal of Comparative Psychology, 112(3), 317-322. https://doi.org/10.1037/07357036.112.3.317

Biegler, R., \& Morris, R. G. M. (1996). Landmark stability: Studies exploring whether the perceived stability of the environment influences spatial representation. Journal of Experimental Biology, 199(1), 187-193.

Blalock, L. D., Sawyer, B. D., Kiken, A., Gutzwiller, R. S., McGill, C. L., \& Clegg, B. A. (2014). Cognitive load while driving impairs memory of moving but not stationary elements within the environment. Journal of Applied Research in Memory and Cognition, 3(2), 95-100.

Bullens, J., Klugkist, I., \& Postma, A. (2011). The role of local and distal landmarks in the development of object location memory. Developmental Psychology, 47(6), 1515.

Caduff, D., \& Timpf, S. (2008). On the assessment of landmark salience for human navigation. Cognitive Processing, 9(4), 249-267. https://doi.org/ 10.1007/s10339-007-0199-2

Carassa, A., Geminiani, G., Morganti, F., \& Varotto, S. (2002). Active and passive spatial learning in a complex environment: The effect of efficient exploration. Cognitive Processing, 4, 65-81.

Chan, E., Baumann, O., Bellgrove, M. A., \& Mattingley, J. B. (2012). From objects to landmarks: The function of visual location information in spatial navigation. Frontiers in Psychology, 3, 11. https://doi.org/10.3389/fpsyg. 2012.00304

Chrastil, E. R., \&Warren, W. H. (2012). Active and passive contributions to spatial learning. Psychonomic Bulletin \& Review, 19(1), 1-23.

Clark, A. (2017). Embodied, situated, and distributed cognition. In W. Bechtel \& G. Graham (Eds.), A companion to cognitive science (pp. 506-517). Wiley.

Cochran, L. M., \& Dickerson, A. E. (2019). Driving while navigating: On-road driving performance using GPS or printed instructions. Canadian Journal of Occupational Therapy, 86(1), 61-69.

Cohen, R., \& Schuepfer, T. (1980). The representation of landmarks and routes. Child Development, 51(4), 1065-1071. https://doi.org/10.2307/1129545

Daniel, M. P., Tom, A., Manghi, E., \& Denis, M. (2003). Testing the value of route directions through navigational performance. Spatial Cognition and Computation, 3(4), 269-289.

De Condappa, O. (2016). The use of landmark-based wayfinding strategies across the adult lifespan (Order No. 10302668). Available from ProQuest Dissertations \& Theses A\&l. (1865273825).

Diersch, N., \&Wolbers, T. (2019). The potential of virtual reality for spatial navigationresearch across the adult lifespan. Journal of Experimental Biology, 222(Suppl_1), 187252.

Doeller, C. F., \& Burgess, N. (2008). Distinct error-correcting and incidental learning of location relative to landmarks and boundaries. PNAS Proceedings of the National Academy of Sciences of the United States of America, 105(15), 5909-5914. https://doi.org/10.1073/pnas.0711433105

Duncan, J. (1984). Selective attention and the organization of visual information. Journal of Experimental Psychology: General, 113(4), 501.

Dunteman, G. H., \& Ho, M. H. R. (2006). An introduction to generalized linear models (Vol. 145). Sage.

Ekstrom, A. D., \& Isham, E. A. (2017). Human spatial navigation: Representations acrossdimensions and scales. Current Opinion in Behavioral Sciences, 17, 84-89.

Evans, G. W., Skorpanich, M. A., Gärling, T., Bryant, K. J., \& Bresolin, B. (1984). The effects of pathway configuration, landmarks and stress on environmental cognition. Journal of Environmental Psychology, 4(4), 323-335. https:// doi.org/10.1016/S0272-4944(84)80003-1 
Farrell, M. J., Arnold, P., Pettifer, S., Adams, J., Graham, T., \& MacManamon, M. (2003). Transfer of route learning from virtual to real environments. Journal of Experimental Psychology: Applied, 9(4), 219-227. https://doi. org/10.1037/1076-898X.9.4.219

Foglia, L., \& Wilson, R. A. (2013). Embodied cognition. Wiley Interdisciplinary Reviews: Cognitive Science, 4(3), 319-325.

Foo, P., Warren, W. H., Duchon, A., \& Tarr, M. J. (2005). Do humans integrate routes into a cognitive map? Map-Versus landmark-based navigation of novel shortcuts. Journal of Experimental Psychology: Learning Memory and Cognition, 31(2), 195-215. https://doi.org/10.1037/0278-7393.31.2. 195

$\mathrm{Fu}, \mathrm{X}$., He, S., Du, J., \& Ge, T. (2019). Effects of in-vehicle navigation on perceptual responses and driving behaviours of drivers at tunnel entrances: A naturalistic driving study. Journal of Advanced Transportation, 2019, 13. https://doi.org/10.1155/2019/9468451

Gagnon, S. A., Brunyé, T. T., Gardony, A., Noordzij, M. L., Mahoney, C. R., \& Taylor, H. A. (2014). Stepping into a map: Initial heading direction influences spatial memory flexibility. Cognitive Science, 38(2), 275-302. https://doi. org/10.1111/cogs. 12055

Gardony, A., Brunyé, T. T., Mahoney, C. R., \& Taylor, H. A. (2011). Affective states influence spatial cue utilization during navigation. Presence: Teleoperators and Virtual Environments, 20(3), 223-240. https://doi.org/10.1162/ PRES_a_00046

Grant, S. C., \& Magee, L. E. (1998). Contributions of proprioception to navigation in virtual environments. Human Factors, 40(3), 489-497.

Gračanin, D. (2018). Immersion versus embodiment: Embodied cognition for immersive analytics in mixed reality environments. In International conference on augmented cognition (pp. 355-368). Cham: Springer.

Hamilton, D. A., Driscoll, I., \& Sutherland, R. J. (2002). Human place learning in a virtual Morris water task: Some important constraints on the flexibility of place navigation. Behavioural Brain Research, 129, 159-170. https:// doi.org/10.1016/S0166-4328(01)00343-6

Han, X., \& Becker, S. (2014). One spatial map or many? Spatial coding of connectedenvironments. Journal of Experimental Psychology: Learning, Memory, andCognition, 40(2), 511.

Hollan, J., Hutchins, E., \& Kirsh, D. (2000). Distributed cognition: Toward a new foundation for human-computer interaction research. ACM Transactions on Computer-Human Interaction (TOCHI), 7(2), 174-196.

Hartley, T., Maguire, E. A., Spiers, H. J., \& Burgess, N. (2003). The well-worn route and the path less traveled: Distinct neural bases of route following and wayfinding in humans. Neuron, 37(5), 877-888. https://doi.org/10.1016/ S0896-6273(03)00095-3

Hejtmánek, L., Oravcová, I., Motýl, J., Horáček, J., \& Fajnerová, I. (2018). Spatial knowledge impairment after GPS guided navigation: Eye-tracking study in a virtual town. International Journal of Human Computer Studies, 116, 15-24. https://doi.org/10.1016/j.ijhcs.2018.04.006

Hurlebaus, R., Basten, K., Mallot, H. A., \& Wiener, J. M. (2008). Route learning strategies in a virtual cluttered environment. In C. Freksa (Ed.), Spatial cognition VI: Learning, reasoning and talking about space. Lecture notes in computer science (Vol. 5248, pp. 104-120). Springer.

Ishikawa, T., Fujiwara, H., Imai, O., \& Okabe, A. (2008). Wayfinding with a GPSbased mobile navigation system: A comparison with maps and direct experience. Journal of Environmental Psychology, 28(1), 74-82. https:// doi.org/10.1016/j.jenvp.2007.09.002

Jacobs, W. J., Laurance, H. E., \& Thomas, K. G. F. (1997). Place learning in virtual space I: Acquisition, overshadowing, and transfer. Learning and Motivation, 28(4), 521-541. https://doi.org/10.1006/Imot.1997.0977

Jansen-Osmann, P. (2002). Using desktop virtual environments to investigate the role of landmarks. Computers in Human Behavior, 18(4), 427-436. https://doi.org/10.1016/S0747-5632(01)00055-3

Jansen-Osmann, P., \& Fuchs, P. (2006). Wayfinding behavior and spatial knowledge of adults and children in a virtual environments: The role of landmarks. Experimental Psychology, 53(3), 171-181. https://doi.org/10. 1027/1618-3169.53.3.171

Janzen, G., \& Van Turennout, M. (2004). Selective neural representation of objects relevant for navigation. Nature Neuroscience, 7(6), 673-677.

Keshavarz, B., Ramkhalawansingh, R., Haycock, B., Shahab, S., \& Campos, J. L. (2018). Comparing simulator sickness in younger and older adults during simulated driving under different multisensory conditions. Transportation Research Part F: Traffic Psychology and Behaviour, 54, 47-62.
Klatzky, R. L. (1998). Allocentric and egocentric spatial representations: Definitions, distinctions and interconnections. In C. Freska, C. Habel, \& K. F. Wender (Eds.), Spatial cognition (pp. 1-17). Springer.

Knierim, J. J., \& Hamilton, D. A. (2011). Framing spatial cognition: Neural representations ofproximal and distal frames of reference and their roles in navigation. Physiological Reviews, 91(4), 1245-1279.

Knorr, F., Chmura, T., \& Schreckenberg, M. (2014). Route choice in the presence of a toll road: The role of pre-trip information and learning. Transportation Research Part F: Traffic Psychology and Behaviour, 27, 44-55.

Kunishige, M., Fukuda, H., lida, T., Kawabata, N., Ishizuki, C., \& Mlyaguchi, H. (2019). Spatial navigation ability and gaze switching in older drivers: A driving simulator study. Hong Kong Journal of Occupational Therapy, $32(1), 22-31$.

Leshed, G., Velden, T., Rieger, O., Kot, B., \& Sengers, P. (2008). In-car GPS navigation: Engagement with and disengagement from the environment. In Proceedings of ACM conference on human factors in computing systems (CHI'08) (pp. 1675-1684). ACM Press.https://doi.org/10.1145/1357054. 1357316

Lin, J. J., Duh, H. B. L., Parker, D. E., Abi-Rached, H., \& Furness, T. (2002). Effects of field of view on presence, enjoyment, memory, and simulator sickness in a virtual environment. Proceedings IEEE Virtual Reality. https://doi.org/ $10.1109 / \mathrm{vr} .2002 .996519$

Lin, C. T., Chuang, C. H., Kerick, S., Mullen, T., Jung, T. P., Ko, L. W., Chen, S. A., King, J. T., \& McDowell, K. (2016). Mind-wandering tends to occur under low perceptual demands during driving. Scientific Reports, 6, 1-11. https:// doi.org/10.1038/srep21353

Livingstone-Lee, S. A., Murchison, S., Zeman, P. M., Gandhi, M., van Gerven, D., Stewart, L., Livingston, N. J., \& Skelton, R. W. (2011). Simple gaze analysis and special design of a virtual Morris water maze provides a new method for differentiating egocentric and allocentric navigational strategy choice. Behavioural Brain Research, 225(1), 117-125. https://doi. org/10.1016/j.bbr.2011.07.005

Loomis, J. M., Klatzky, R. L., Golledge, R. G., Cicinelli, J. G., Pellegrino, J. W., \& Fry, P. A. (1993). Nonvisual navigation by blind and sighted: assessment of path integration ability. Journal of Experimental Psychology: General, 122(1), 73.

Maguire, E. A., Gadian, D. G., Johnsrude, I. S., Good, C. D., Ashburner, J., Frackowiak, R. S., \& Frith, C. D. (2000). Navigation-related structural change in the hippocampi oftaxi drivers. Proceedings of the National Academy of Sciences, 97(8), 4398-4403.

Maguire, E. A., Woollett, K., \& Spiers, H. J. (2006). London taxi drivers and bus drivers: A structural MRI and neuropsychological analysis. Hippocampus, 16(12), 1091-1101.

McNamara, T. P., Hardy, J. K., \& Hirtle, S. C. (1989). Subjective hierarchies in spatialmemory. Journal of Experimental Psychology: Learning, Memory, and Cognition, 15(2), 211.

Mizell, D. W., Jones, S. P., Slater, M., \& Spanlang, B. (2002). Comparing immersive virtual reality with other display modes for visualizing complex $3 \mathrm{D}$ geometry. London: University College London. http://www.cs.ucl.ac.uk/resea $\mathrm{rch} / \mathrm{vr} /$ Projects/Immersion/Experiment2/paper.pdf.

Montello, D. R. (2005). Navigation. In P. Shah \& A. Miyake (Eds.), The Cambridge handbook of visuospatial thinking (pp. 257-294). Cambridge, UK: Cambridge University Press. https://doi.org/10.1017/CBO9780511610448. 008

Mueller, S. C., Jackson, C. P. T., \& Skelton, R. W. (2008). Sex differences in a virtual water maze: An eye tracking and pupillometry study. Behavioural Brain Research, 193(2), 209-215. https://doi.org/10.1016/j.bbr.2008.05.017

Münzer, S., Zimmer, H. D., Schwalm, M., Baus, J., \& Aslan, I. (2006). Computerassisted navigation and the acquisition of route and survey knowledge. Journal of Environmental Psychology, 26(4), 300-308. https://doi.org/10. 1016/j.jenvp.2006.08.001

Narayan, M., Waugh, L., Zhang, X., Bafna, P., \& Bowman, D. (2005). Quantifying thebenefits of immersion for collaboration in virtual environments. Proceedings of theACM Symposium on Virtual Reality Software and Technology, 05, 78-81. https://doi.org/10.1145/1101616.1101632

O'Keefe, J., \& Nadel, L. (1978). The hippocampus as a cognitive map. Oxford University Press.

O'Laughlin, E. M., \& Brubaker, B. S. (1998). Use of landmarks in cognitive mapping: Gender differences in self report versus performance. Personality and Individual Differences, 24(5), 595-601. https://doi.org/10.1016/ S0191-8869(97)00237-7 
Patrick, E., Cosgrove, D., Slavkovic, A., Rode, J. A., Verratti, T., \& Chiselko, G. (2000). Using a large projection screen as an alternative to head-mounted displays for virtual environments. In Proceedings of the SIGCHI conference on Human factors in computing systems (pp. 478-485).

Pankok, C., Jr., \& Kaber, D. (2018). The effect of navigation display clutter on performance and attention allocation in presentation-and simulatorbased driving experiments. Applied Ergonomics, 69, 136-145.

Pausch, R., Proffitt, D., \& Williams, G. (1997). Quantifying immersion in virtual reality. In Proceedings of the 24th annual conference on Computer graphics and interactive techniques (pp. 13-18).

Péruch, P., Vercher, J.-L., \& Gauthier, G. M. (1995). Acquisition of spatial knowledgethrough visual exploration of simulated environments. Ecological Psychology, 7(1), 1-20. https://doi.org/10.1207/s15326969eco0701_1

Poucet, B. (1993). Spatial cognitive maps in animals: New hypotheses on their structure andneural mechanisms. Psychological Review, 100(2), 163.

Poucet, B., \& Save, E. (2017). Sensorimotor integration: Spatial cognitive maps. Reference Module in Neuroscience and Biobehavioral Psychology. Elsevier, ISBN 9780128093245. https://doi.org/10.1016/B978-0-12-809324-5. 02743-7.

Ruddle, R. A., Volkova, E., Mohler, B., \& Bülthoff, H. H. (2011). The effect of landmark and body-based sensory information on route knowledge. Memory and Cognition, 39(4), 686-699. https://doi.org/10.3758/ s13421-010-0054-z

Save, E., \& Poucet, B. (2000). Involvement of the hippocampus and associative parietal cortex in the use of proximal and distal landmarks for navigation. Behavioural Brain Research, 109(2), 195-206.

Siegel, A. W., \& White, S. H. (1975). The development of spatial representations of large-scale environments. In H. W. Reese (Ed.), Advances in Child Development and Behaviour (Vol. 10, pp. 9-55). Academic Press.

Smyth, C. C. (2007). Sensitivity of subjective questionnaires to cognitive loading while driving with navigation aids: A pilot study. Aviation, Space, and Environmental Medicine, 78(5), B39-B50.

Soler, J. L., Contero, M., \& Alcañiz, M. (2017, November). VR serious game design based on embodied cognition theory. In Joint International Conference on Serious Games (pp. 12-21). Cham: Springer.

Sorrows, M. E., \& Hirtle, S. C. (1999, August). The nature of landmarks for real and electronic spaces. In International conference on spatial information theory (pp. 37-50). Berlin: Springer.

Starkweather, G. K. (2003). DSHARP_a wide-screen multi-projector display. Journal of Optics a: Pure and Applied Optics, 5(5), S136.

Stankiewicz, B. J., \& Kalia, A. A. (2007). Acquisition of structural versus object landmark knowledge. Journal of Experimental Psychology: Human Perception and Performance, 33(2), 378-390. https://doi.org/10.1037/ 0096-1523.33.2.378

Steck, S. D., \& Mallot, H. A. (2000). The role of global and local landmarks in virtual environment navigation. Presence: Teleoperators and Virtual Environments, 9(1), 69-83. https://doi.org/10.1162/105474600566628

Von Stülpnagel, R., \& Steffens, M. C. (2012). Can active navigation be as good as driving? A comparison of spatial memory in drivers and backseat drivers. Journal of Experimental Psychology: Applied, 18(2), 162.

Tan, D. S., Gergle, D., Scupelli, P., \& Pausch, R. (2006). Physically large displays improveperformance on spatial tasks. ACM Transactions on ComputerHuman Interaction, 13, 71-99.

Taylor, H. A., Naylor, S. J., \& Chechile, N. A. (1999). Goal-specific influences on the representation of spatial perspective. Memory \& Cognition, 27(2), 309-319. https://doi.org/10.3758/BF03211414

Thorndyke, P. W., \& Hayes-Roth, B. (1982). Differences in spatial knowledge acquired from maps and navigation. Cognitive Psychology, 14(4), 560-589. https://doi.org/10.1016/0010-0285(82)90019-6

Tolman, E. C. (1948). Cognitive maps in rats and men. Psychological Review, 55(4), 189-208.

Török, Á., Nguyen, T. P., Kolozsvári, O., Buchanan, R. J., \& Nadasdy, Z. (2014). Referenceframes in virtual spatial navigation are viewpoint dependent. Frontiers in Humanneuroscience, 8, 646.

Tyndiuk, F., Lespinet-Najib, V., Thomas, G., \& Schlick, C. (2007). Impact of tasks and users'characteristics on virtual reality performance. Cyberpsychology \& Behavior, 10(3), 444-452.

Viaud-Delmon, I., \& Warusfel, O. (2014). From ear to body: The auditory-motor loop in spatial cognition. Frontiers in Neuroscience, 8, 283. https://doi org/10.3389/fnins.2014.00283
Waller, D., \& Lippa, Y. (2007). Landmarks as beacons and associative cues. Memory \& Cognition, 35(5), 910-924. https://doi.org/10.3758/BF03193465

Wallet, G., Sauzéon, H., Rodrigues, J., \& N'Kaoua, B. (2008). Use of virtual reality for spatial knowledge transfer: Effects of passive/active exploration mode in simple and complex routes for three different recall tasks. Bordeaux: Paper presented at the ACM Symposium on Virtual Reality Software and Technology.

Wallet, G., Sauzéon, H., Pala, P. A., Larrue, F., Zheng, X., \& N'Kaoua, B. (2011). Virtual/real transfer of spatial knowledge: Benefit from visual fidelity provided in a virtual environment and impact of active navigation. Cyberpsychology, Behavior, and Social Networking, 14, 417-423.

Weech, S., Wall, T., \& Barnett-Cowan, M. (2020). Reduction of cybersickness during and immediately following noisy galvanic vestibular stimulation. Experimental Brain Research, 238, 427-437. https://doi.org/10.1007/ s00221-019-05718-5

Wiener, J. M., Büchner, S. J., \& Hölscher, C. (2009). Taxonomy of human wayfinding tasks: A knowledge-based approach. Spatial Cognition and Computation, 9(2), 152-165. https://doi.org/10.1080/13875860902906496

Wiener, J. M., Schnee, A., \& Mallot, H. A. (2004). Use and interaction of navigation strategies in regionalized environments. Journal of Environmental Psychology, 24(4), 475-493. https://doi.org/10.1016/j.jenvp.2004.09.006

Wilkinson, G. N., \& Rogers, C. E. (1973). Symbolic description of factorial models for analysis of variance. Journal of Royal Statistics Society, 22, 392-399.

Willis, K. S., Hölscher, C., Wilbertz, G., \& Li, C. (2009). A comparison of spatial knowledge acquisition with maps and mobile maps. Computers, Environment and Urban Systems, 33(2), 100-110. https://doi.org/10.1016/j. compenvurbsys.2009.01.004

Wilson, P. N., \& Alexander, T. (2008). Blocking of spatial learning between enclosure geometry and a local landmark. Journal of Experimental Psychology: Learning Memory and Cognition, 34(6), 1369-1376. https://doi.org/10. 1037/a0013011

Wilson, M. (2002). Six views of embodied cognition. Psychonomic Bulletin \& Review, 9, 625-636. https://doi.org/10.3758/BF03196322

Whishaw, I. Q., \& Wallace, D. G. (2003). On the origins of autobiographical memory. Behavioural Brain Research, 138(2), 113-119.

Wolbers, T., \& Hegarty, M. (2010). What determines our navigational abilities? Trends in Cognitive Sciences, 14(3), 138-146.

Wolbers, T., \& Wiener, J. M. (2014). Challenges for identifying the neural mechanisms that support spatial navigation: the impact of spatial scale. Frontiers in Human Neuroscience, 8, 571.

Yi, J., Lee, H. C. Y., Parsons, R., \& Falkmer, T. (2015). The effect of the global positioning system on the driving performance of people with mild Alzheimer's disease. Gerontology, 61(1), 79-88.

Zhang, H., Zherdeva, K., \& Ekstrom, A. D. (2014). Different "routes" to a cognitive map: Dissociable forms of spatial knowledge derived from route and cartographic maplearning. Memory \& Cognition, 42(7), 1106-1117.

Zhong, J. Y., \& Kozhevnikov, M. (2016). Relating allocentric and egocentric survey-based representations to the self-reported use of a navigation strategy of egocentric spatial updating. Journal of Environmental Psychology, 46, 154-175. https://doi.org/10.1016/j.jenvp.2016.04.007

Zimmer, H. D. (2004). The construction of mental maps based on a fragmentary view ofphysical maps. Journal of Educational Psychology, 96, 603-610.

\section{Publisher's Note}

Springer Nature remains neutral with regard to jurisdictional claims in published maps and institutional affiliations. 